\title{
manejo de Plantas Daninhas no Consórcio de Milho com CAPIM-BRAQUIÁRIA (Brachiaria decumbens) ${ }^{1}$
}

\author{
Weed Management in Corn and Signal Grass (Brachiaria decumbens) Intercrops
}

\author{
JAKELAITIS, A. ${ }^{2}$, SILVA, A.A. ${ }^{3}$, FERREIRA, L.R. ${ }^{3}$, SILVA, A.F. ${ }^{4}$ e FREITAS, F.C.L. ${ }^{2}$
}

\begin{abstract}
RESUMO - Objetivou-se neste trabalho avaliar os efeitos do nicosulfuron em mistura com atrazine sobre espécies daninhas e produção de milho e de Brachiaria decumbens cultivados em consórcio, nos sistemas de plantios direto e convencional. Foram avaliadas

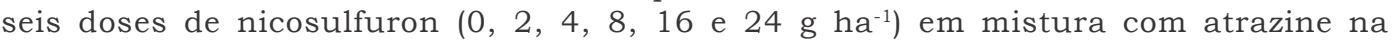
dose de $1.500 \mathrm{~g} \mathrm{ha}^{-1}$, mais duas testemunhas capinadas, representadas por ambas as espécies em monocultivo. As espécies daninhas anuais de propagação seminífera foram controladas com eficiência pelo nicosulfuron a partir de $8 \mathrm{~g}^{\text {ha }} \mathrm{e}^{-1} \mathrm{em}$ mistura com atrazine, independentemente do sistema de plantio. Ao contrário, as espécies perenes (Artemisia verlotorum e Cyperus rotundus) de propagação vegetativa não foram controladas pela mistura de herbicidas, independentemente da dose aplicada. As maiores infestações destas espécies foram observadas no sistema convencional de plantio. Quanto a $B$. decumbens, esta teve sua biomassa reduzida no consórcio com o milho, quando comparado com sua testemunha em monocultivo, sendo maior a redução quando submetida às maiores doses do nicosulfuron, em ambos os sistemas de plantio. Não se observou diferença quanto à produção de grãos e de palhada de milho, em função dos tratamentos estudados, tanto para o plantio direto quanto para o convencional.
\end{abstract}

Palavras-chave: sistemas de manejo, nicosulfuron, atrazine.

ABSTRACT - The objective of this work was to evaluate the effects of nicosulfuron and atrazine mixture on weeds, corn and Brachiaria decumbens intercrops, cultivated under no-tillage and conventional tillage. Six nicosulfuron doses $\left(0,2,4,8,16\right.$ and $\left.24 \mathrm{~g} \mathrm{ha}^{-1}\right)$ in mixture with atrazine in the dose of $1.500 \mathrm{~g} \mathrm{ha}^{-1}$ were evaluated, plus two controls, represented by both species in monocrop. Seminiferous propagation of the annual weeds was efficiently controlled by applying nicosulfuron in $8 \mathrm{~g} \mathrm{ha}^{-1}$ in mixture with atrazine, regardless of the management systems. The perennial species (Artemisia verlotorum and Cyperus rotundus), of vegetative propagation, were not controlled by the herbicide mixture, regardless of the applied dose. Larger infestations of these species were observed under the conventional system. B. decumbens biomass was reduced in the intercrop with corn, when compared to its control in monocrop, presenting a greater reduction when submitted to the largest doses of nicosulfuron, in both planting systems. No difference was observed in the production of grains and corn straw, in function of the treatments studied, under both planting systems.

Key words: management systems, nicosulfuron, atrazine.

Recebido para publicação em 30.3.2004 e na forma revisada em 17.12.2004.

Pesquisa financiada com apoio do CNPq.

2 Doutorando, Departamento de Fitotecnia da Universidade Federal de Viçosa - UFV, 36570-000 Viçosa-MG; ${ }^{3}$ Prof., Departamento de Fitotecnia - UFV; ${ }^{4}$ Bolsista de iniciação científica. 


\section{INTRODUÇÃO}

O milho é um dos principais cereais cultivados no mundo, fornecendo produtos para a alimentação humana e animal e matériaprima para a indústria. No Brasil, a cultura ocupa posição significativa na economia, em decorrência do valor da produção agropecuária, da área cultivada e do volume produzido, especialmente nas regiões Sul, Sudeste e Centro-Oeste. Considerando sua importância econômica, recentemente têm ocorrido importantes mudanças nos sistemas de produção da cultura, ressaltando sua expansão nos sistemas de plantio direto e de integração lavoura-pecuária (Glat, 2002).

Devido aos grandes investimentos necessários para a formação, recuperação e reforma de pastagens, têm-se buscado diversas técnicas visando a diminuição desses investimentos. Entre estas técnicas, a utilização do consórcio de culturas com forrageiras tem sido preconizada na formação e reforma de pastagens, produção de forragem para confinamento, bem como de cobertura morta para plantio direto de culturas. Esta técnica tem como objetivo atenuar os custos relativos à correção e adubação do solo e ao controle de plantas daninhas, pois, além de formação e recuperação das pastagens, permite a produção de grãos (Sousa Neto, 1993; Townsend et al., 2000; Cobucci, 2001).

Várias culturas têm sido utilizadas no consórcio com forrageiras, como milho, milheto, sorgo e arroz (Portes et al., 2000). As vantagens proporcionadas pelo sistema consorciado, citadas por Sousa Neto (1993), são os efeitos residuais dos fertilizantes aplicados para o cultivo anual, a diminuição de infestação de plantas daninhas, a proteção do solo contra a erosão e o aumento da produção de forragem em uma mesma estação de crescimento.

No Cerrado brasileiro tem-se pesquisado o sistema de integração agricultura-pecuária em plantio direto, que consiste na implantação de cultivo consorciado de culturas anuais com espécies forrageiras (Cobucci, 2001). De acordo com Oliveira et al. (2001), nesse agroecossistema cultiva-se seqüencialmente um a dois monocultivos por ano, mais o cultivo de uma cultura safrinha, consistindo do consórcio de uma cultura precoce com a forrageira, geralmente espécies do gênero Brachiaria. Dentre estas se destaca Brachiaria decumbens, popularmente conhecida como capim-braquiária, que é originária da África e tem sido amplamente disseminada pelas regiões tropicais do mundo, devido às suas qualidades como forrageira (Lorenzi \& Souza, 2000). Ela se destaca por apresentar excelente adaptação a solos de baixa fertilidade, fácil estabelecimento e considerável produção de biomassa durante o ano, proporcionando excelente cobertura vegetal do solo (Alvim et al., 1990). Pela sua agressividade e resistência, é também considerada importante espécie daninha da maioria das culturas anuais e perenes.

O estabelecimento da forrageira com uma cultura consorciada ocorre sob condições de competição entre elas, principalmente em plantio simultâneo. Assim, segundo OzierLafontaine et al. (1997), nem sempre se obtém sucesso devido ao efeito competitivo que uma espécie exerce sobre a outra. O conhecimento de como a forrageira e a cultura consorciada são afetadas pela competição por fatores de produção é de grande importância para o êxito na formação da pastagem e produção satisfatória da cultura (Sousa Neto, 1993). O milho é considerado excelente competidor com plantas de porte baixo, pois apresenta crescimento inicial rápido. Trabalhos conduzidos por Alvim et al. (1989) e Duarte et al. (1995) demonstraram que, em competição com espécies de Brachiaria, a produtividade do milho não foi alterada. No consórcio de $B$. brizantha com o milho, Cobucci (2001) relata que em vários ensaios a presença da forrageira não afetou o milho e, em outros, foi necessário o uso de nicosulfuron em subdoses para reduzir o crescimento da forrageira e, com isso, garantir o bom rendimento da cultura. No entanto, os consórcios são sistemas complexos, e a forma como é implantada a cultura, associada com a forrageira, a época de estabelecimento, a disposição das plantas e a infestação por plantas daninhas, pode influenciar a competição entre as plantas. Objetivou-se nesta pesquisa avaliar os efeitos de doses reduzidas do herbicida nicosulfuron em mistura com atrazine no manejo de plantas daninhas e na produtividade do consórcio de milho com $B$. decumbens, nos sistemas de plantios convencional e direto. 


\section{MATERIAL E MÉTODOS}

Dois experimentos foram conduzidos nos sistemas de plantios convencional e direto em um Argissolo Vermelho-Amarelo câmbico, no período de novembro de 2001 a abril de 2002, em Coimbra-MG. A análise das amostras de solo, coletadas antes da instalação dos experimentos na área destinada ao plantio convencional, apresentou as seguintes características químicas: $\mathrm{pH}$ em água de 5,0; 1,01 dag $\mathrm{kg}^{-1}$ de matéria orgânica; 9,6 mg dm de $\mathrm{P} ; 50 \mathrm{mg} \mathrm{dm}{ }^{-3}$ de $\mathrm{K}$; e Ca, $\mathrm{Mg}, \mathrm{H}+\mathrm{Al} \mathrm{e} \mathrm{CTC}$ de 2,$0 ; 0,5 ; 2,5$; e $5,12 \mathrm{cmol}_{\mathrm{c}} \mathrm{dm}^{-3}$, respectivamente. Em plantio direto, os valores corresponderam a pH em água de 5,0; 1,07 dag $\mathrm{kg}^{-1}$ de matéria orgânica; 7,1 $\mathrm{mg} \mathrm{dm}^{-3}$ de P; $59 \mathrm{mg} \mathrm{dm}^{-3}$ de K; e Ca, Mg, H + Al e CTC de 2,3; 0,6; 2,6; e $5,65 \mathrm{cmol}_{\mathrm{c}} \mathrm{dm}^{-3}$, respectivamente.

Antecedendo a instalação dos ensaios, a comunidade infestante era composta por Artemisia verlotorum (losna), Cyperus rotundus (tiririca), Cynodon dactylon (grama-seda), Sorghum arundinaceum (falso-massambará) e Brachiaria plantaginea (capim-marmelada). Devido à presença de plantas daninhas perenes de propagação vegetativa em ambos os ensaios, foi realizada a dessecação química com os herbicidas glyphosate + 2,4-D (1,44+ $0,335 \mathrm{~kg} \mathrm{ha}^{-1}$, respectivamente) em mistura no tanque, três semanas antes da semeadura. No ensaio referente ao plantio convencional, essa vegetação dessecada foi incorporada pelo preparo mecânico do solo com uma aração e duas gradagens, sete dias antes da semeadura, enquanto no plantio direto ela permaneceu na superficie do solo. O controle das plantas daninhas que germinaram após essas operações foi feito com a aplicação de paraquat $\left(0,5 \mathrm{~kg} \mathrm{ha}^{-1}\right)$ imediatamente após a semeadura do milho e de Brachiaria decumbens.

O híbrido de milho AG 6690 foi semeado no espaçamento entre fileiras de $0,90 \mathrm{~m}$, com aproximadamente sete sementes por metro, sendo utilizados $400 \mathrm{~kg} \mathrm{ha}^{-1}$ da formulação 828-16 (N-P-K) na linha de plantio. Brachiaria decumbens cv. Basilisk foi semeada no espaçamento de 0,45 m entre linhas (duas linhas na entrelinha, nos tratamentos consorciados) e na profundidade de $1 \mathrm{~cm}$, sendo utilizados $3,0 \mathrm{~kg} \mathrm{ha}^{-1}$ de sementes viáveis. A semeadura simultânea dessas espécies foi realizada em
29 de novembro de 2001, com máquina específica para plantio direto (Semeato SHM $11 / 13)$, em ambos os ensaios. A adubação de cobertura foi feita quatro semanas após a emergência do milho, aplicando-se o equivalente a $90 \mathrm{~kg} \mathrm{ha}^{-1}$ de nitrogênio na forma de uréia. Os demais tratos culturais foram realizados durante a condução do experimento e seguiram as recomendações técnicas indicadas para a cultura do milho (Fancelli \& Dourado Neto, 2000). Os dados climatológicos do período de condução do ensaio estão apresentados na Figura 1.

Os ensaios foram arranjados no delineamento de blocos completos ao acaso, com quatro repetições. As unidades experimentais mediram $10 \times 14 \mathrm{~m}$. Os tratamentos foram constituídos do consórcio de milho com $B$. decumbens, submetidos a doses crescentes do herbicida nicosulfuron $(0,2,4,8,16 \mathrm{e}$ $24 \mathrm{~g} \mathrm{ha}^{-1}$ ) mais a dose fixa de atrazine (1.500 $\mathrm{g} \mathrm{ha}^{-1}$ ) em mistura no tanque, além das duas testemunhas, representadas pelas duas espécies em monocultivo. Nos tratamentos com herbicidas, as aplicações foram feitas aos 20 dias após a emergência do milho (DAE), no estádio de quatro folhas totalmente expandidas e quando a maioria das plantas de braquiária iniciava o perfilhamento. Os herbicidas foram aplicados com pulverizador costal pressurizado a $\mathrm{CO}_{2}$, com pressão constante de 3,0 kgf $\mathrm{cm}^{-2}$, utilizando bicos Turbo Teejet $110^{\circ} 02$, pulverizando o equivalente a $100 \mathrm{~L} \mathrm{ha}^{-1}$ de calda. Nas testemunhas solteiras o controle das plantas daninhas foi feito por capinas manuais, quando necessário.

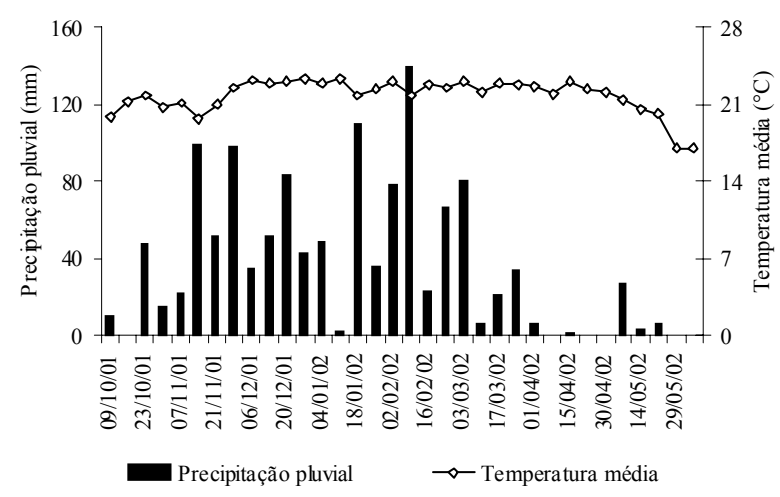

Figura 1 - Médias semanais de precipitação pluvial e temperatura obtidas durante a condução dos ensaios. Viçosa-MG, 2002.

Planta Daninha, Viçosa-MG, v. 22, n. 4, p. 553-560, 2004 
Antecedendo a aplicação dos herbicidas, a comunidade infestante no plantio convencional foi composta principalmente de Cyperus rotundus, Brachiaria plantaginea, Artemisia verlotorum, Bidens pilosa e Ipomoea grandifolia. No plantio direto, as plantas daninhas predominantes foram Brachiaria plantaginea, Artemisia verlotorum, Cyperus rotundus, Sorghum arundinaceum, Bidens pilosa e Digitaria horizontalis. A eficiência dos tratamentos sobre o controle da população de plantas daninhas foi avaliada aos 30 dias após a aplicação (DAA) dos herbicidas, por meio de quatro amostragens ao acaso na parcela, com o uso de um quadrado de 0,5 m de lado, recolhendo-se todas as plantas presentes. As plantas daninhas coletadas foram levadas ao laboratório, onde foram separadas por espécie, contadas e secas em estufa por 72 horas a $70{ }^{\circ} \mathrm{C}$, para determinação da biomassa seca.

Avaliou-se a biomassa seca de $B$. decumbens colhida de quatro amostras de $1,0 \mathrm{~m}^{2}$, efetuadas ao acaso na parcela, aos 30 DAA dos herbicidas e na colheita do milho aos 140 DAE. No milho foi determinada a produção de grãos e de palhada, considerando as três fileiras centrais de $5 \mathrm{~m}$ de comprimento.

A análise estatística dos dados foi feita separadamente para cada ensaio, e em seguida foi feita a análise conjunta, contrastando ambos os sistemas de manejo. Os resultados significativos, em função das doses dos herbicidas, foram submetidos à análise de regressão, utilizando o modelo logístico.

\section{RESULTADOS E DISCUSSÃO}

Os resultados da eficiência dos tratamentos, aos 30 DAA, foram discutidos em função da biomassa seca total da comunidade infestante, das espécies perenes de propagação principalmente vegetativa e das anuais de propagação seminifera, conforme detalhado na Tabela 1. Verificou-se diferença significativa para a biomassa seca total das plantas daninhas nas doses de nicosulfuron aplicadas nos plantios convencional e direto $(p<0,01)$ e também entre os sistemas de plantio. O efeito de dose-resposta foi expresso pelo modelo logístico $\hat{Y}=a /\left[1+(x / b)^{c}\right]$, em que "a" correspondeu à resposta de controle na menor dose; "b", ao valor da concentração do herbicida que atingiu $50 \%$ da resposta $\left(\mathrm{I}_{50}\right)$; e "c" descreveu o declive da curva em torno do $\mathrm{I}_{50}$ (Souza et al., 2000). Dessa forma, para a biomassa seca total de plantas daninhas observaram-se maiores valores do $\mathrm{I}_{50}$ no plantio convencional com 4,59 $\mathrm{g} \mathrm{ha}^{-1}$ de nicosulfuron, em relação ao plantio direto $\left(1,18 \mathrm{~g} \mathrm{ha}^{-1}\right)$, significando que o efeito de dose-resposta foi mais intenso no plantio direto, com maior eficiência de controle à medida que foram aumentadas as doses do nicosulfuron (Figura 2). Entretanto, esse efeito no total de plantas daninhas foi atribuido à presença das espécies perenes de propagação vegetativa; nestas, a eficiência proporcionada pelos herbicidas foi nula (Figura 3).

Para as espécies perenes de propagação vegetativa (Artemisia verlotorum e Cyperus rotundus) não se observaram diferenças entre

Tabela 1 - Participação percentual de biomassa das espécies daninhas nos plantios convencional (PC) e direto (PD) aos 30 dias após a aplicação dos herbicidas (DAA). Viçosa-MG, 2002

\begin{tabular}{|c|c|c|c|c|c|c|}
\hline \multirow{2}{*}{ Espécie } & \multicolumn{2}{|c|}{$\begin{array}{c}\text { Total de plantas } \\
\text { daninhas (\%) }\end{array}$} & \multicolumn{2}{c|}{$\begin{array}{c}\text { Propagação } \\
\text { seminífera (\%) }\end{array}$} & \multicolumn{2}{c|}{$\begin{array}{c}\text { Propagação } \\
\text { vegetativa (\%) }\end{array}$} \\
\cline { 2 - 7 } & PC & PD & PC & PD & PD & PC \\
\hline Artemisia verlotorum & 15,04 & 17,78 & - & - & 47,89 & 21,01 \\
\hline Brachiaria plantaginea & 25,29 & 59,09 & 89,03 & 93,98 & - & - \\
\hline Cyperus rotundus & 56,55 & 19,34 & - & - & 52,11 & 78,98 \\
\hline Digitaria horizontalis & 0 & 1,08 & 0 & 1,71 & - & - \\
\hline Eleusine indica & 2,92 & 0,88 & 10,27 & 1,41 & - & - \\
\hline Emilia sonchifolia & 0 & 0,44 & 0 & 0,70 & - & - \\
\hline Ipomoea grandifolia & 0,06 & 0 & 0,20 & 0 & - & - \\
\hline Sorghum arundinaceum & 0,14 & 1,39 & 0,50 & 2,20 & - & - \\
\hline
\end{tabular}




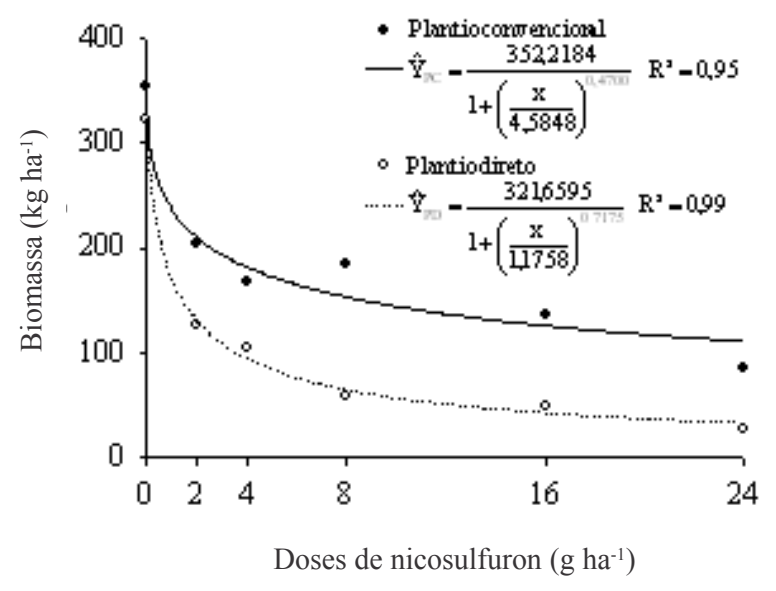

Figura 2 - Biomassa seca total de plantas daninhas aos 30 dias após a aplicação dos herbicidas, em função de doses de nicosulfuron, nos sistemas de plantios convencional (PC) e direto (PD). Viçosa-MG, 2002.

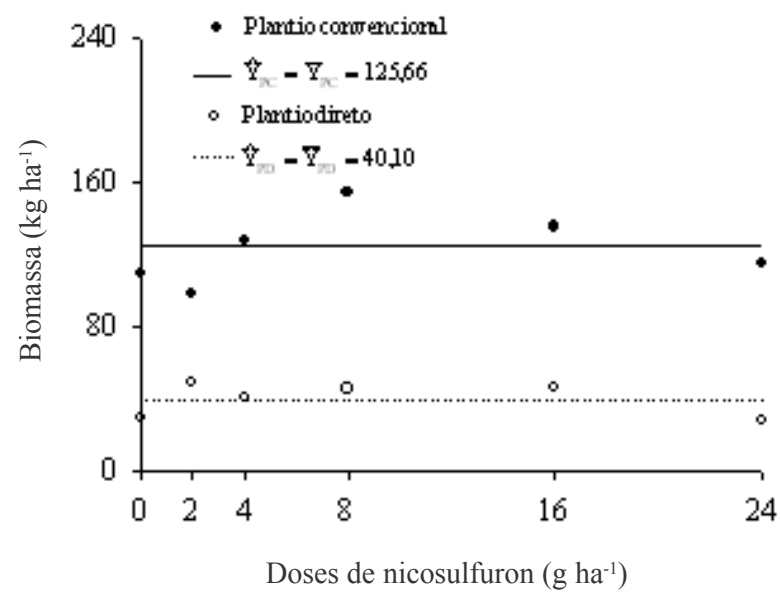

Figura 3 - Biomassa seca das plantas daninhas perenes de propagação vegetativa (C. rotundus mais $A$. verlotorum) aos 30 dias após a aplicação dos herbicidas, em função de doses de nicosulfuron, nos sistemas de plantios convencional (PC) e direto (PD). Viçosa-MG, 2002.

as doses estudadas, constatando-se apenas efeito dos sistemas de plantio, prevalecendo maior infestação no plantio convencional (Figura 3). A agressividade destas espécies está relacionada, entre outros fatores, à sua habilidade de propagação; assim, plantas que são capazes de se propagar sexuada e assexuadamente se tornam mais dificeis de ser controladas em relação às de propagação exclusivamente seminífera. A. verlotorum e
C. rotundus possuem um sistema assexuado de reprodução, constituído principalmente por rizomas e tubérculos, respectivamente, os quais contêm alta reserva nutritiva, que lhes garante a perpetuação e rápida reinfestação das áreas agrícolas submetidas ao preparo mecânico do solo (Santos, 1992; Godoy et al., 1995; Ferreira et al., 2000). C. rotundus em plantio direto apresenta redução na densidade e na taxa de acúmulo de biomassa seca da parte aérea e do banco de tubérculos, bem como redução da viabilidade destes em relação às populações que se desenvolvem no sistema de preparo convencional do solo (Jakelaitis et al., 2003). Essa resposta é atribuída ao manejo integrado proporcionado pelo controle químico com herbicidas dessecantes sistêmicos aplicados em pré-plantio, associado ao controle cultural conferido pelo não-revolvimento do solo e pela adoção de culturas competitivas por luminosidade.

Nas espécies anuais de propagação seminífera observou-se somente o efeito entre as doses de nicosulfuron $(\mathrm{p}<0,01)$, com resultados semelhantes em ambos os sistemas estudados (Figura 4). A maior eficiência de controle foi obtida quando se aumentaram as doses do herbicida, apresentando seu $I_{50}$ inferior a $1,5 \mathrm{~g} \mathrm{ha}^{-1}$ de nicosulfuron e eficiência máxima de controle a partir da dose de $8 \mathrm{~g} \mathrm{ha}^{-1}$. Essa dose situou-se abaixo das obtidas por Bastiani (1997), o qual observou, nas doses de 30, 35 e $40 \mathrm{~g} \mathrm{ha}^{-1}$ de nicosulfuron em mistura com 750,875 e $1.000 \mathrm{~g} \mathrm{ha}^{-1}$ de atrazine, respectivamente, controle entre 70 e $90 \%$ para B. plantaginea em aplicações iniciais e superior a $90 \%$ para espécies daninhas dicotiledôneas, principalmente Bidens pilosa, Ipomoea grandifolia e Galinsoga parviflora.

A biomassa de $B$. decumbens aos 30 DAA e no momento da colheita mecânica do milho diferiu apenas para as doses do herbicida $(\mathrm{p}<0,01)$. O limite superior de 501,67 $\mathrm{kg} \mathrm{ha}^{-1}$ de biomassa da forrageira no modelo de regressão empregado correspondeu à resposta desta na dose zero de nicosulfuron, destacando, dessa forma, o efeito competitivo do milho sobre a forrageira, com redução do incremento de biomassa de $28,7 \%$, quando comparado à testemunha solteira, que produziu $703,68 \mathrm{~kg} \mathrm{ha}^{-1}$ de biomassa aos 30 DAA dos herbicidas (Figura 5). No entanto, 
esse efeito foi mais pronunciado na colheita do milho, quando $B$. decumbens permaneceu por período mais prolongado competindo com a cultura, apresentando $1.535,41 \mathrm{~kg} \mathrm{ha}^{-1}$ de biomassa produzida na dose zero de nicosulfuron, enquanto a produção da forrageira na mesma época no monocultivo representou $6.176,66 \mathrm{~kg} \mathrm{ha}^{-1}$, proporcionando inibição de $75,14 \%$ do acúmulo de biomassa de $B$. decumbens ao longo do período de convivência com o milho (Figura 6). No consórcio do milho com B. brizantha, Cobucci (2001)

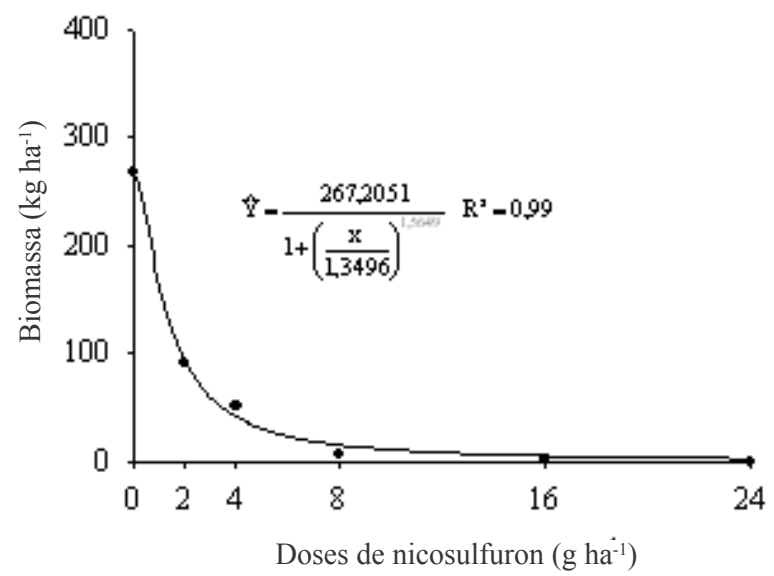

Figura 4 - Biomassa seca de plantas daninhas anuais de propagação seminífera aos 30 dias após a aplicação dos herbicidas, em função de doses de nicosulfuron. ViçosaMG, 2002.

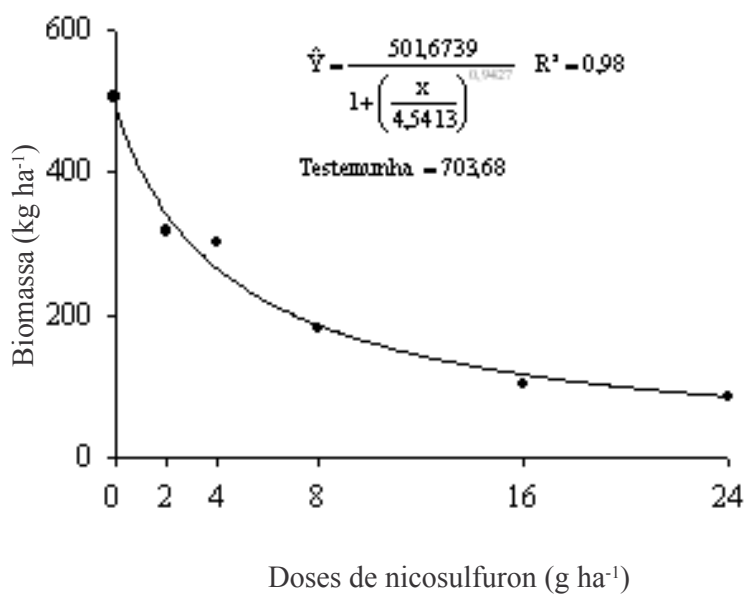

Figura 5 - Biomassa seca de B. decumbens consorciada com milho aos 30 dias após a aplicação dos herbicidas, em função de doses de nicosulfuron. Viçosa-MG, 2002. relata que o milho apresentou taxa de acúmulo de biomassa superior à da forrageira aos 25 DAE e que esta, em monocultivo, apresentou aumento da taxa de crescimento somente aos 45 DAE. Assim, em consórcio, o acúmulo de biomassa da forrageira foi retardado, devido ao sombreamento e à competição exercida pelo milho. Castro et al. (1999), estudando a produção de biomassa seca de $B$. decumbens sob vários níveis de sombreamento, verificaram que o decréscimo em sua produtividade pode ser decorrente do fato de a radiação do ambiente sombreado ser inferior ao seu ponto de compensação luminoso. Contudo, Dias Filho (2000) constatou, em estudos referentes ao comportamento de forrageiras tropicais sob sombreamento artificial, que $B$. brizantha e $B$. humidicola apresentaram plasticidade fenotípica quanto à captura de radiação em resposta ao sombreamento e que elas alocaram significativamente menos biomassa nas raízes e aumentaram a alocação para as folhas, com incremento da área foliar específica e da razão de área foliar. Conseqüentemente, foram capazes de manter o crescimento em niveis satisfatórios, mesmo com limitação luminosa.

Plântulas de $B$. decumbens são consideradas suscetiveis (85 a 95\% de controle) em aplicações iniciais de nicosulfuron nas doses comerciais recomendadas (Lorenzi, 2000). Dessa forma, em relação à resposta de doseefeito para a biomassa seca da forrageira, o

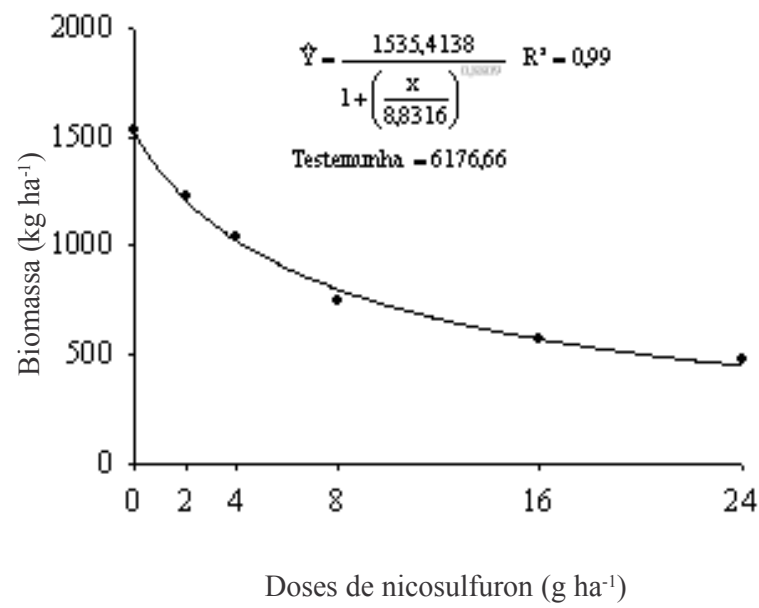

Figura 6 - Biomassa seca de $B$. decumbens consorciada com milho no dia da colheita deste, em função de doses de nicosulfuron. Viçosa-MG, 2002. 
valor do $\mathrm{I}_{50}$ foi de 4,54 e de 8,83 $\mathrm{g} \mathrm{ha}^{-1}$ de nicosulfuron aos 30 DAA dos herbicidas e na colheita, respectivamente, com efeito deletério à medida que a dose foi aumentada. Em estudos de absorção, translocação e metabolismo de nicosulfuron em B. platyphylla, Gallaher et al. (1999) verificaram que a maior atividade do nicosulfuron sobre esta espécie se deve à rápida absorção e translocação para as regiões meristemáticas. Este herbicida inibe a acetolactato sintase (ALS), uma enzima importante na síntese dos aminoácidos ramificados valina, isoleucina e leucina (Hinz \& Owen, 1996), e a rápida translocação do inibidor da ALS para as regiões meristemáticas contribui para a maior atividade herbicida, pois esta enzima é mais ativa em tecidos em desenvolvimento (Gerwick et al., 1993). Todavia, o aumento do $\mathrm{I}_{50}$ no momento da colheita do milho pode estar associado ao secamento deste no final do ciclo, permitindo a entrada de radiação no dossel e favorecendo, com isso, a recuperação da forrageira.

Não foram observadas diferenças significativas quanto à produção de grãos e de palhada de milho entre doses e sistemas de plantio, destacando-se que não houve interferência significativa de $B$. decumbens na produção de milho (Figura 7). A produção desta cultura no monocultivo capinado foi superior em $481 \mathrm{~kg} \mathrm{ha}^{-1}$ de grãos, em relação à média do sistema consorciado, com a convivência da forrageira e das espécies daninhas. Resultados semelhantes, quanto ao rendimento de grãos de milho cultivados em consórcio com

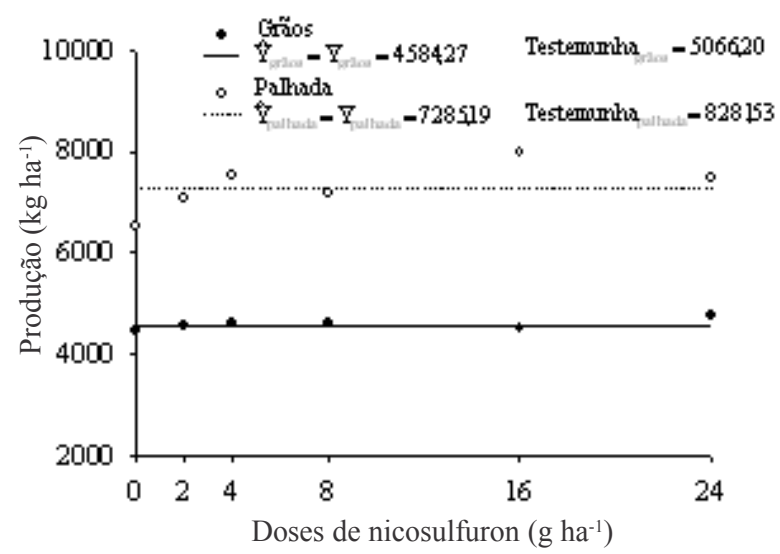

Figura 7 - Rendimento de grãos e de palhada de milho, em função de doses de nicosulfuron. Viçosa-MG, 2002.
$B$. brizantha e solteiro, foram apresentados por Cobucci (2001).

De forma geral, observou-se viabilidade agronômica tanto na produção do milho quanto no estabelecimento da forrageira, atendendo aos objetivos de formação de pastagem, bem como de aumento na produção de palhada para cobertura morta do solo, após a colheita mecânica do milho. Entretanto, torna-se necessário avaliar a contribuição do consórcio na supressão de plantas daninhas, quando comparado aos monocultivos em competição com estas, verificando-se a viabilidade de uso de subdoses de sulfoniluréias, sob determinadas infestações.

\section{LITERATURA CITADA}

ALVIM, J. M. et al. Métodos de estabelecimento de Brachiaria decumbens em associação com a cultura do milho. R. Bras. Zootec., v. 18, n.5, p. 417-425, 1989.

ALVIM, M. J. et al. Aplicação de nitrogênio em acessos de braquiária. 1. Efeito sobre a produção de matéria seca. Past. Tropic., v. 12, n. 2, p. 2-6, 1990.

BASTIANI, M. L. R. Atividade dos herbicidas nicosulfuron e atrazine, em condições de casa de vegetação e de campo. 1997. 59 f. Tese (Mestrado em Fitotecnia) - Universidade Federal de Viçosa, Viçosa, 1997.

CASTRO, C. R. T. et al. Produção forrageira de gramíneas cultivadas sob luminosidade reduzida. R. Bras. Zootec. v. 28, n. 5, p. 919-927, 1999.

COBUCCI, T. Manejo integrado de plantas daninhas em sistema de plantio direto. In: ZAMBOLIM, L. Manejo Integrado Fitossanidade: cultivo protegido, pivô central e plantio direto. Viçosa: UFV, 2001. p. 583-624.

DIAS FILHO, M. B. Growth and biomass allocation of the $\mathrm{C}_{4}$ grasses Brachiaria brizantha and B. humidicola under shade. Pesq. Agropec. Bras., v. 35, n. 12, p. 2335-2341, 2000 .

DUARTE, J. M. et al. Producción de maíz (Zea mays L.), soya (Glycine max L.) y caupi (Vigna ungiculata) sembrados en asociación con gramíneas en el trópico húmedo. Past. Tropic., v. 17, n. 2, p. 12-19, 1995.

FANCELLI, A. L.; DOURADO-NETO, D. Produção de milho. Guaíba: 2000. 360 p.

FERREIRA, F. A. et al. Manejo integrado de plantas daninhas em hortaliças. In: ZAMBOLIM, L. (Ed.) Manejo integrado de doenças, pragas e plantas daninhas. Viçosa: Universidade Federal de Viçosa, 2000. p. 365-372.

Planta Daninha, Viçosa-MG, v. 22, n. 4, p. 553-560, 2004 
GALLAHER, K. et al. Absorption, translocation and metabolism of primisulfuron and nicosulfuron in broadleaf signalgrass (Brachiaria platyphylla) and corn. Weed Sci., v. 47 , p. $8-12,1999$.

GERWICK, B. C. et al. Rapid diagnosis of ALS/AHAS resistant weeds. Weed Technol., v. 7, p. 519-524, 1993.

GLAT, D. Perspectivas do milho para 2002. Plantio Direto, v. 69, p. 15-17, 2002.

GODOY, G. et al. El tipo de labranza afecta la flora y la distribución vertical del banco de semillas de malezas. Ceiba, v. 36, n. 2, p. 217-219, 1995.

HINZ, J. R.; OWEN, M. K. Nicosulfuron and primisulfuron selectivity in corn and two grass weeds. Weed Sci., v. 44, p. 219-223, 1996.

JAKELAITIS, A. et al. Efeitos de sistemas de manejo sobre a população de tiririca. Planta Daninha, v. 21, n. 1, p. 8995, 2003.

LORENZI, H. Manual de identificação e controle de plantas daninhas: plantio direto e convencional. 5.ed. Nova Odessa: Plantarum, 2000. 384 p.

LORENZI, H.; SOUZA, H. M. Plantas daninhas do Brasil: terrestres, aquáticas, parasitas e tóxicas. Nova Odessa: Plantarum, 2000. 349 p.
OliVeIRA, I. P. et al. Palhada no Sistema Santa Fé. Goiânia: EMBRAPA-CNPAF, 2001. 4 p. (Informações Agronômicas, 93)

OZIER-LAFONTAINE, $\mathrm{H}$ et al. Radiation and transpiration partitioning in a maize-sorghum intercrop: test and evaluation of two models. Field Crops Res., v. 49, p. 127-145, 1997.

PORTES, T. A. et al. Análise do crescimento de uma cultivar de braquiária em cultivo solteiro e consorciado com cereais. Pesq. Agropec. Bras., v. 35, n. 7, p.1349-1358, 2000.

SANTOS, A. M. B. Crescimento, partição de assimilados da losna (Artemisia verlotorum Lamotte) e seu controle químico. 1992. $94 \mathrm{f}$. Tese (Mestrado em Fitotecnia) - Universidade Federal de Viçosa, Viçosa, 1992.

SOUZA NETO, J. M. Formação de pastagens de Brachiaria brizantha cv. Marandu com o milho como cultura acompanhante. 1993. 58 f. Dissertação (Mestrado em Fitotecnia) - Escola Superior de Agricultura “Luiz de Queiroz", Piracicaba, 1993.

SOUZA, A. P. et al. Lixiviação do glyphosate e imazapyr em solos com diferentes texturas e composição química: métodos do bioensaio. Planta Daninha, v. 18, n. 1, p. 5-16, 2000.

TOWNSEND, C. R. et al. Renovação de pastagens degradadas em consórcio com milho na Amazônia Ocidental. In: CONGRESSO NACIONAL DE MILHO E SORGO, 18., 2000, Uberlândia. Anais... Uberlândia: ABMS. CD-ROM 